WellBeing International

WBI Studies Repository

12-1999

\title{
Social Mechanisms Enhance Escape Responses in Shoals of Rainbowfish, Melanotaenia duboulayi
}

Culum Brown

University of Queensland

Kevin Warburton

University of Queensland

Follow this and additional works at: https://www.wellbeingintlstudiesrepository.org/acwp_aff

Part of the Animal Studies Commons, Behavior and Ethology Commons, and the Comparative Psychology Commons

\section{Recommended Citation}

Brown, C., \& Warburton, K. (1999). Social mechanisms enhance escape responses in shoals of rainbowfish, Melanotaenia duboulayi. Environmental Biology of Fishes, 56(4), 455-459.

This material is brought to you for free and open access by WellBeing International. It has been accepted for inclusion by an authorized administrator of the WBI Studies Repository. For more information, please contact wbisr-info@wellbeingintl.org.

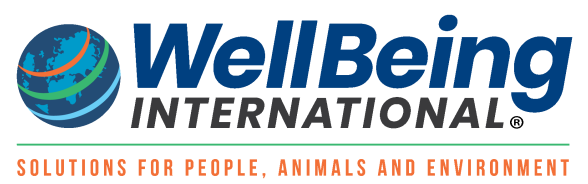




\title{
Social Mechanisms Enhance Escape Responses in Shoals of Rainbowfish, Melanotaenia duboulayi
}

\author{
Culum Brown \& Kevin Warburton \\ The University of Queensland
}

\author{
KEYWORDS \\ behavioural monitoring, trawl avoidance, Pisces, Melanotaeniidae
}

\begin{abstract}
Shoaling behaviour has been shown to provide many benefits to group members. In this study we examined the ability of fish shoals to escape from a novel trawl apparatus. Fish in shoals of 5 found, and escaped through, a hole in the oncoming trawl more quickly than fish in pairs. Fish in the larger shoals displayed a significant decrease in escape latencies over a series of five trawls, providing clear evidence of net avoidance learning, whereas fish in pairs showed no evidence of learning over successive runs. Observations suggested that more information on the location of the escape route was available to fish in larger shoal sizes owing to social stimulation.
\end{abstract}

\section{Introduction}

Nets and other fishing gear invoke responses in fishes resembling that of predator avoidance (Francis \& Williams 1995) which has been shown to be facilitated by social learning (Suboski et al. 1990, Krause 1993, Mathis et al. 1996). Larger groups are thought to benefit from increased vigilance, which improves predator detection (Elgar 1989, Lima 1995). The phenomenon of collective detection assumes that all members of a group are alerted to the presence of a predator once a single group member has detected it (Lima 1995). Predator detection is followed by a fright response which rapidly spreads through the group, providing an early warning to those members that have not independently perceived the approaching threat (Godin \& Morgan 1985, Godin et al. 1988). For example, in shoaling fish, fright responses move rapidly through the group resulting in synchronized schooling behaviours. The behaviour of an individual fish within a school is largely dependent on the behaviour of those around it. The speed of transmission of information through the school far exceeds that of the approaching predator (the 'Trafalgar effect': Treherne \& Foster 1981). Shoaling fish thus provide an opportunity to study the flow of information between members of a group and how individuals monitor and respond to the behavior of other group members.

A further benefit arising from the formation of groups is an increase in the probability that at least one member will discover a solution to a problem (e.g. show an effective escape response). Group members are more likely to make the 'right' decision more quickly and with greater accuracy than they otherwise 
would in isolation (Grunbaum 1997). Increased shoal size facilitates information transfer and social learning which may be particularly important in detecting novel predators, exploiting novel food types or solving spatial problems. We might, therefore, hypothesise that larger groups of fish may solve novel problems sooner and the solution to the problem may spread more rapidly through the group. In this study we tested the hypotheses that by monitoring the behaviour of their shoal mates, fish in larger shoals (1) discover the location of an escape route sooner, and (2) through successive exposure, learn the location of the escape route more rapidly.

\section{Methods}

Duboulay's rainbowfish, Melanotaenia duboulayi, were captured using bait traps set in Amamoor Creek $\left(26^{\circ} 21^{\prime} \mathrm{S}, 152^{\circ} 40^{\prime} \mathrm{E}\right)$, a tributary of the Mary River in south-east Queensland. After being transported to the University of Queensland, the fish were held in a large holding tank (75 × $60 \times 25 \mathrm{~cm}$ deep) in the laboratory for several months prior to experimentation, allowing them ample time to adjust to captive conditions. After two days in captivity all fish readily accepted flake food. The average standard length of rainbowfish used during the experiment was 51:9 $\pm 1: 4 \mathrm{~mm}$ (mean_SE). Both in the wild and in the laboratory members of the family Melanotaenidae regularly form shoals and show effective anti-predator schooling responses in the presence of predators (Brown \& Warburton 1997). Shoal size in the wild varies from 5 to over 20 individuals. Singletons and groups smaller than five are much rarer and commonly consist of males in search of mating opportunities (personal observation).

An experimental tank measuring $200 \times 30 \times 30 \mathrm{~cm}$ was equipped with a pulley system that allowed a vertical net to be pulled along the long axis of the tank. The depth of the water in the tank was maintained at $20 \mathrm{~cm}$ and the temperature at $23^{\circ} \mathrm{C}$. The net had a mesh size of $1 \mathrm{~cm}$ and completely blocked the tank with the exception of a small hole. The hole $(2 \times 2 \mathrm{~cm})$ was placed in the centre of the net about $10 \mathrm{~cm}$ from the bottom of the tank and $14 \mathrm{~cm}$ from each side. The fish could use this hole to avoid being trapped as the net was dragged from one end to the other.

A group of fish was randomly selected from the holding tank, placed in the experimental tank and allowed to adjust to the new surroundings for $15 \mathrm{~min}$. The net was drawn along the tank until it was $3 \mathrm{~cm}$ from the end, at which point it was held in position for $60 \mathrm{~s}$. The time taken for the net to move from one end to the other was $30 \mathrm{~s}$. Any fish that did not escape through the net during motion thus became trapped. Fish which did not escape were allocated the maximum time limit of $90(30+60)$ seconds. The net was then removed and placed back in its original position. This constituted one run. The procedure was repeated at 2 min intervals in order to investigate the effect of negative experience (i.e. being trapped) and the effect of escaping on the learning ability of the fish. For each run the mean time taken for the shoal to escape through the hole was recorded, together with other general observations. Each group of fish was exposed to a total of 5 runs and each group was used once. Three people carried out the procedure. An observer called out the time as fish escaped through the hole and made general observations on the orientation and behaviour of the fish, another recorded the data, while a third wound the pulley handle. The first two experimenters sat motionless approximately $2 \mathrm{~m}$ from the tank while the third was hidden from the fish behind a barrier erected in the tank.

Groups of two and five fish were tested (10 replicates of each). The latency data were non-normally distributed because some fish did not escape from the trawl within the $90 \mathrm{~s}$ limit. A Wilcoxon 2-sample test was used to examine the shoal size effect and a Kruskal-Wallis test (chi-square approximation) was used to examine the effect of run number for each shoal size. The statistics were performed using the SAS1 system. 


\section{Results}

Fish in groups of five consistently found the escape hole more quickly than fish in pairs (Figure 1). The number of exposures (run number) had a significant effect on escape latency for groups of five but not for groups of two over the five runs (Table 1). Groups of five fish decreased their mean ( \pm SE) escape time from $74 \pm 7$ to $47 \pm 5 \mathrm{~s}$ in five runs. By contrast, groups of two fish showed no significant learning effect and a larger amount of variability in escape latencies between runs.

During the first run all fish searched for an escape route. Of the 10 replicate groups, only one replicate group of two successfully found the hole during the first run. By contrast, fish from groups of five discovered and escaped through the hole during their first exposure in $50 \%$ of the replicates. Once the net had stopped moving and was held in position, the intensity of searching increased until an individual succeeded in escaping. Although no quantitative information was collected on fish orientation, general observations suggested that the outcome of a trial appeared to vary depending on the orientation and location of the remaining fish. Fish that were orientated towards the escaping fish seemed to be attracted to the region where the hole was located. Fish that were not orientated towards escapees (and thus unable to monitor their behaviour) often remained trapped for the remainder of the run.

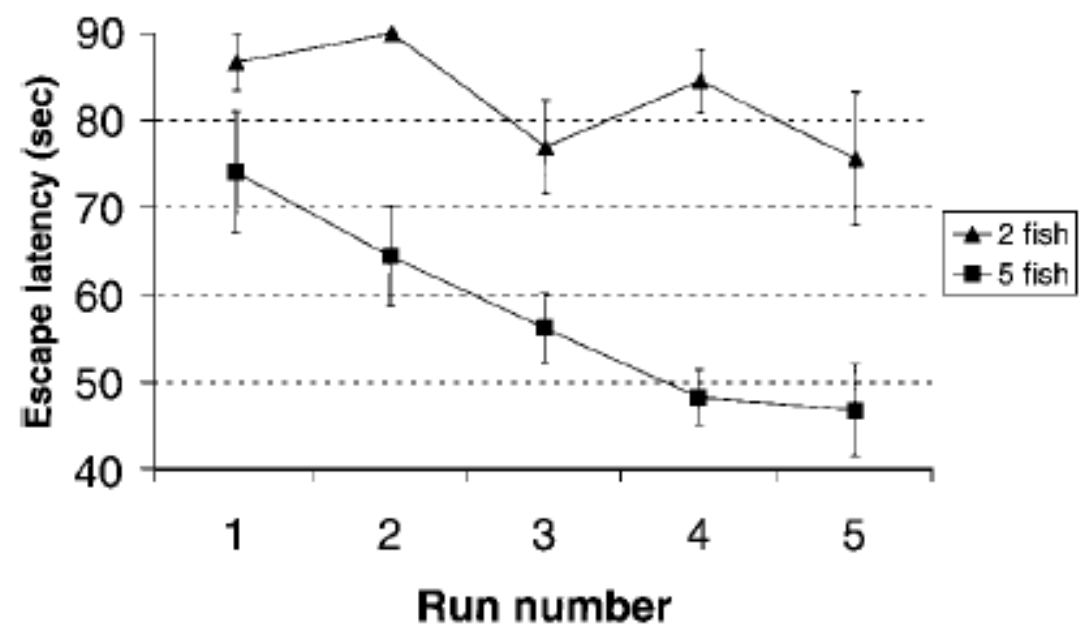

Figure 1. The mean escape latency in seconds $( \pm S E)$ for fish in groups of two (triangles) and groups of five (squares) over five runs $(n=10$ in each case).

After four or five runs the groups of five swam with the net, keeping just in front of it. This behaviour is commonly seen in schools of fish avoiding trawls in the wild (Engas 1994). Close to the end of the tank they turned and swam calmly through the hole. Others simply moved to the far end of the tank, waited for the net to come to them, and then escaped. In contrast, the groups of two were more erratic. Rarely did a group of two find the hole by the end of the fourth or fifth run. Only 3\% of fish in pairs escaped the trawl while it was still in motion compared with $14.8 \%$ of fish from groups of five. From our general observations it appeared that fish in the smaller groups spent most of their time with their heads facing away from the net as it moved. Fish in groups of five tended to be at varying distances and at different angles to the net, some facing it as it came towards them. Fish facing the net appeared to locate the hole sooner. 
Table 1. Escape latency: (1) Results of Wilcoxon 2-sample test (normal approximation, with continuity correction of 0.5 ) for shoal size effect between populations, and (2) Kruskal-Wallis test (chi-square approximation) for run effect within each shoal size.

\begin{tabular}{|lccc|}
\hline (1) Shoal size effect & \multicolumn{3}{c|}{} \\
\cline { 2 - 4 } Run 1 & $\mathbf{S}$ & $\mathbf{Z}$ & Prob $>|\mathbf{Z}|$ \\
\cline { 2 - 4 } Run 2 & 85.5 & -1.77075 & 0.0766 \\
Run 3 & 55.0 & -3.99806 & 0.0001 \\
Run 4 & 75.0 & -2.25992 & 0.0238 \\
Run 5 & 56.0 & -3.78782 & 0.0002 \\
Total & 75.0 & -2.45239 & 0.0142 \\
& 1658.0 & -6.24542 & 0.0001 \\
(2) Run effect & & & \\
& & & \\
Shoal size = 2 & $\mathbf{X}^{2}$ & Df & Prob > $\mathbf{X}^{\mathbf{2}}$ \\
Shoal size =5 & 7.613 & 4 & 0.1068 \\
\hline
\end{tabular}

\section{Discussion}

Fishes, like other vertebrates, show strong avoidance responses towards negative stimuli and are quick to make associations to avoid such stimuli in future encounters. Pyanov (1993), for example, showed that fishes increase their defensive behaviour and learn to avoid trawls after just one exposure both in the laboratory and under natural conditions. Much of the learning that occurs in fish shoals may well be socially mediated and consequently dependent on shoal size. Hunter \& Wisby (1964) investigated the net avoidance behavior of carp using gear similar to that used in the present study and found that groups of fish were much more successful at avoiding capture than isolates. As with the carp in Hunter \& Wisby's study, rainbowfish in groups of five frequently escaped while the net was still moving, whereas individuals were more likely to escape the net once it became stationary or became captured. Hunter \& Wisby (1964) failed to pay close attention to the behaviour of individuals within the groups and accordingly could not explain the factors that may have led to the shorter reaction times observed over repeated runs in their study. From our observations it seems likely that the orientation of fish at the time of initial escape was important in determining the fate of the rest of the group.

Hale (1956) found that even when 'leadership' (i.e. the capacity of certain individuals to constantly perform better) was experimentally reduced, groups consistently escaped more rapidly than singletons. Furthermore, the scores obtained when individuals were tested in groups bore no relationship to the scores obtained when those individuals were tested alone. These results indicate that improved group escape responses are the result of social interactions. In our study, the faster initial escape latency and the higher rate of decrease in escape time over repeated runs observed in larger groups were unlikely to be the result of leaders or the presence of superior escapees.

Larger groups of fish tend to be bolder in the face of threat, and threat dilution appears to permit individuals to better concentrate on activities such as exploration and foraging (Magurran \& Pitcher 1983, Smith \& Warburton 1992). Welty (1934) suggested that goldfish escaped from a maze more quickly in a group due to elevated group cohesion, which resulted in increased exploration activity. Individuals in larger groups may have paid closer attention to the spatial details of the net and may have also detected 
the net coming towards them earlier, thus giving them more time to search for an escape route (early predator warning, Lazarus 1979).

Pitcher et al. (1982) showed that fish in larger shoals locate food faster than singletons. Information regarding the location of food is passed passively to shoal mates by a display of feeding behaviour, thus attracting conspecifics to the location (Pitcher \& House 1987). The feeding responses of individuals are not independent, and social cues displayed by successful foragers inform other fish where to find food (Ryer \& Olla 1992). The mechanisms underlying the responses observed in this experiment are probably very similar to those seen in forage patch copying. In this instance the cue for escape success may have been the movement of fish through the net which attracted conspecifics to the general area of the escape hole. This social facilitation (Clayton 1978) probably contributed to the faster escape times for fish in larger shoals.

In the current experiment, the rapid decrease in escape latencies displayed by the fish in groups of five may have been influenced by individuals monitoring the behaviour of fellow shoal mates and benefiting from a discovery made by any one of them. This is supported by the fact that after the first fish escaped, others often followed in quick succession. Hale (1956) attributed group success in green sunfish, Lepomis cyanellus, to 'mutual stimulation'. Fish grouping behaviour may also rely on guided social learning (Laland \& Williams 1997) where the attention of an observer is attracted to a particular stimulus by a social model. The observer then interacts with the stimulus and relies on individual learning to complete the task. The rate of learning within a social group increases with the number of times the particular behaviour is successfully performed or the number of 'tutors' performing it (Giraldeau et al. 1994).

Fish that did not find the hole but followed others through it while escaping may have contributed less to the rediscovery of the escape route during subsequent runs. Previous experiments using groups of five fish indicate that the individual that locates the hole first is more likely to escape during future runs (C. Brown unpublished data). On many occasions members of smaller shoals found the hole during an early trial but failed to do so during the trials that followed it, perhaps because they had less assistance from other individuals in rediscovering it. More consistent searching responses are expected from larger shoals owing to the nature of the principal components of schooling behaviour (Grunbaum 1997). As shoal size increases inter-individual variation decreases due to behavioural averaging (Fitzsimmons \& Warburton 1992). Such an effect may explain why the learning curve displayed by the fish in groups of five was not only steeper but also far smoother than that of fish in pairs.

Exploration and threat detection are facilitated by larger group sizes. Fish in larger shoals may also benefit from the discoveries made by their shoalmates. As shoal size increases the likelihood that an individual discovers the solution to a novel problem increases, as does the probability that another individual observes the solution being carried out. This results not only in a solution on first exposure to a problem, but also in an elevated rate of learning for the group as a whole.

\section{Acknowledgements}

Thanks are due to Australian Geographic for partially funding this project and to the students of ZL 331 .

\section{References cited}

Brown, C. \& K. Warburton. 1997. Predator recognition and antipredator responses in the rainbowfish Melanotaenia eachamensis. Behav. Ecol. Sociobiol. 41: 61-68.

Clayton, D.A. 1978. Socially facilitated behaviour. Quart. Review Biol. 53: 373-392.

Elgar, M.A. 1989. Predator vigilance and groups size in mammals and birds: a critical reviewof the empirical evidence. Biological Reviews 64: 13-33. 
Engas, A. 1994. The effects of trawl performance and fish behaviour on the catching efficiency of demersal sampling trawls. pp. 45-65. In: A. Ferno \& S. Olsen (ed.) Marine Fish Behaviour in Capture and Abundance Estimation, Fishing News Books, Oxford.

Fitzsimmons, S.D. \& K. Warburton. 1992. Fish movement behaviour: variability within and between groups. Behavioural Processes 26: 211-216.

Francis, M.P. \& M.W. Williams. 1995. Diel variation in trawl catch rates of Pagrus auratus (Sparidae). Fisheries Research 24: 301-310.

Giraldeau, L.-A., T. Caraco \& T.J. Valone. 1994. Social foraging: individual learning and cultural transmission of innovations. Behav. Ecol. 5: 35-43.

Godin, J.G.J., L.J. Classon \& M.V. Abrahams. 1988. Group vigilance and shoal size in a small characin fish. Behaviour 104: 29-40.

Godin, J.G.J.\&M. Morgan. 1985. Predator avoidance and school size in a cypinidontid fish (Fundulus diaphanus, Lesueur). Behav. Ecol. Sociobiol. 16: 105-110.

Grunbaum, D. 1997. Schooling as a strategy for taxis in a noisy environment. pp. 257-281. In: J.K. Parrish \& W.M. Hamner (ed.) Animal Groups in Three Dimensions, Cambridge University Press, Cambridge.

Hale, E.B. 1956. Social facilitation and forebrain function in maze performance of green sunfish, Lepomis cyanellus. Physiological Zoology 25: 93-106.

Hunter, J.R. \& W.J.Wisby. 1964. Net avoidance behaviour of carp and other species of fish. J. Fish. Res. Board Can. 21: 613-633.

Krause, J. 1993. Transmission of fright reaction between different species of fish. Behaviour 127: 37-48.

Laland, K.N. \& K. Williams. 1997. Shoaling generated social learning of foraging information in guppies. Anim. Behav. 53: 1161-1169.

Lazarus, J. 1979. Flock size and behaviour in captive red-billed weaver birds (Quelea queala): implications for social facilitation and functions of flocking. Anim. Behav. 71: 127-145.

Lima, S.L. 1995. Back to the basics of anti-predatory vigilance: the group-size effect. Anim. Behav. 49 : 11-20.

Magurran, A.E. \& T.J. Pitcher. 1983. Foraging, timidity and shoal size in minnows and goldfish. Behav. Ecol. Sociobiol. 12: 147-152.

Mathis, A., D.P. Chivers \& R.J.F. Smith. 1996. Cultural transmission of predator recognition in fishes; intraspecific and interspecific learning. Anim. Behav. 51: 185-201.

Pitcher, T.J. \& A. House. 1987. Foraging rules for group feeders: area copying depends upon density in shoaling goldfish. Ethology 76: 161-167.

Pitcher, T.J., A.E. Magurran \& I.J. Winfield. 1982. Fish in larger shoals find food faster. Behav. Ecol. Sociobiol. 10: 149-151.

Pyanov, A.I. 1993. Fish learning in response to trawl fishing. ICES Mar. Sci. Symp. 196: 12-16.

Ryer, C.H. \& B.L. Olla. 1992. Social mechanisms facilitating exploitation of spatially variable ephemeral food patches in pelagic marine fish. Anim. Behav. 44: 69-74.

Smith, M.F.L. \& K. Warburton. 1992. Predator shoaling moderates the confusion effect in blue-green chromis, Chromis viridis. Behav. Ecol. Sociobiol. 30: 103-107.

Suboski, M.D., S. Bain, A.E. Carty, L.M. McQuoid, M.I. Seelen \& M. Seifert. 1990. Alarm reaction in acquisition and social transmission of simulated predator recognition by zebra danio fish (Brachydanio rerio). J. Comp. Psychol. 104: 101-112.

Treherne, J. \& W. Foster. 1981. Group transmission of predator avoidance in a marine insect. Anim. Behav. 28: 1119-1122.

Welty, J.C. 1934. Experiments in group behaviour of fishes. Physiological Zoology 7: 85-182. 